Fixed Point Theory, 20(2019), No. 1, 299-322

DOI: $10.24193 /$ fpt-ro.2019.1.20

http://www.math.ubbcluj.ro/ nodeacj/sfptcj.html

\title{
THE FIXED POINT PROPERTY FOR CLOSED NEIGHBORHOODS OF LINE SEGMENTS IN $L^{p}$
}

\author{
BERND S.W. SCHRÖDER \\ School of Mathematics and Natural Sciences, \\ The University of Southern Mississippi, \\ 118 College Avenue, \#5043, Hattiesburg, MS 39406 \\ E-mail: Bernd.Schroeder@usm.edu
}

\begin{abstract}
We prove that, in $L^{p}$-spaces with $p \in(1, \infty]$, closed neighborhoods of line segments are dismantlable and hence every monotone operator on these neighborhoods has a fixed point. We also give an example that, for $p=1$, closed neighborhoods of line segments need not be dismantlable. It is an open question whether every monotone self map of a closed neighborhood of a line segment in $L^{1}$ has a fixed point.
\end{abstract}

Key Words and Phrases: Dismantlable ordered set, fixed point property, line segment, closed $L^{p}$-neighborhood.

2010 Mathematics Subject Classification: 06A07, 46B42, 47H07, 47H10.

\section{REFERENCES}

[1] A. Abian, Fixed point theorems of the mappings of partially ordered sets, Rend. del Circolo Math. di Palermo, 20(1971), 139-142.

[2] S. Abian, A.B. Brown, A theorem on partially ordered sets with applications to fixed point theorems, Canad. J. Math., 13(1961), 78-82.

[3] M.R. Alfuraidan, M.A. Khamsi, A fixed point theorem for monotone asymptotically nonexpansive mappings, Proc. Amer. Math. Soc., 146(2018), 2451-2456.

[4] M.R. Alfuraidan, M.A. Khamsi, Coupled fixed points of monotone mappings in a metric space with a graph, Fixed Point Theory, 19(2018), 33-44.

[5] S. Carl, S. Heikkilä, Fixed Point Theory in Ordered Sets and Applications, Springer Verlag, 2011.

[6] J. Jachymski, The contraction principle for mappings on a metric space with a graph, Proc. Amer. Math. Soc., 136(2007), 1359-1373

[7] B. Li, E.C. Milner, A chain complete poset with no infinite antichain has a finite core, Order, 10(1993), 55-63.

[8] I. Rival, A fixed point theorem for finite partially ordered sets, J. Comb. Theory (A), 21(1976), 309-318.

[9] M. Roddy, Fixed points and products, Order, 11(1994), 11-14.

[10] M. Roddy, Fixed points and products: width 3, Order, 19(2002), 319-326.

[11] M. Roddy, On an example of Rutkowski and Schröder, Order, 19(2002), 365-366.

[12] B. Schröder, The uniqueness of cores for chain-complete ordered sets, Order, 17(2000), 207-214.

[13] B. Schröder, Ordered Sets - An Introduction with Connections from Combinatorics to Topology, Birkhäuser Verlag, 2016. 
Received: June 13, 2017; Accepted: December 13, $201 \%$. 
